\title{
Filosofia nas Orientações Curriculares para - Ensino Médio e no Enem: lacunas temporais e conceituais
}

\author{
Ester Pereira Neves de Macedo ${ }^{1}$ \\ ORCID: 0000-0002-1908-7279
}

\section{Resumo}

Este artigo analisa a adesão dos itens de filosofia do Exame Nacional do Ensino Médio (Enem) às Orientações Curriculares Nacionais para o Ensino Médio (Ocem), de 2006, como um estudo de caso da relação entre referencial curricular e avaliação em larga escala, usando como referencial teórico o ciclo de políticas de Stephen Ball e Richard Bowe (BALL; BOWE, 1992; BOWE, BALL; GOLD, 1992; MAINARDES, 2006). Este estudo torna-se particularmente relevante dada, por um lado, a intermitência da filosofia nessa etapa de ensino, e, por outro, a iminente reformulação do exame, a partir da publicação da Base Nacional Comum Curricular. Por meio dessa análise, reforça-se a tese de que a operacionalização dos documentos curriculares no exame não é automática, nem garantida. Ao analisar as Ocem como parte de uma rede de políticas educacionais para o ensino médio, da qual o Enem e a nova BNCC também são parte, este artigo visa contribuir para o fortalecimento da filosofia no ensino médio, ao destacar pontos de continuidade e pontos de tensão entre nodos anteriores desta rede. Este estudo é dividido em três partes: 1) um panorama quantitativo da cobertura dos conteúdos de filosofia das Ocem ao longo dos vinte anos do Enem, pontuando lacunas que ainda persistem; 2) apresentação de alguns fatores que explicam essas lacunas, em particular as diferenças nas origens e objetivos de cada um desses instrumentos; 3) análise qualitativa de como as diferenças conceituais entre as Ocem e o Enem se manifestam nas temáticas de filosofia abordadas na prova ao longo dos anos. Como conclusão, apresentam-se alguns pontos de reflexão acerca da perspectiva para a filosofia no exame nesse novo horizonte pós-BNCC.

\section{Palavras-chave}

Filosofia - Enem - Ocem - BNCC - Referenciais curriculares.

1- Universidade de Brasília (UnB) / Instituto Nacional de Estudos e Pesquisas Educacionais Anísio Teixeira (INEP), Brasília, DF, Brasil. Contato: ester.macedo@inep.gov.br 


\title{
Philosophy in the National Curriculum Guidelines (Ocem) and in the National High School Exam (Enem): temporal and conceptual gaps
}

\begin{abstract}
This article analyses the correspondence between the philosophy questions administered in the Brazilian National High School Exam (Enem) and the Brazilian National Curriculum Guidelines (Ocem), published in 2006, as a case study of the relationship between curriculum document and large scale assessment, having as theoretical framework what Stephen Ball and Richard Bow call "policy cycle" (BALL; BOWE, 1992; BOWE, BALL; GOLD, 1992; MAINARDES, 2006). This study becomes particularly relevant given, on the one hand, the intermittence of the offering of philosophy in Brazilian high schools, and, on the other, the imminent reformulation of the exam, to conform to the new National Common Core (BNCC). This study highlights Ball and Bowe's thesis that the "implementation" of curricular documents is neither automatic nor certain. By analyzing the Ocem as part of a web of educational policies for high school, of which the Enem and the BNCC are also part, the present study aims to contribute towards strengthening the place of philosophy in high school, by highlighting points of continuity and points of tension between the preexisting nodes of this web. This article is divided in three parts: 1) a quantitative overview of how the philosophy contents proposed by the Ocem were covered in the exam in the last twenty years, pointing out gaps that still persist; 2) exploration of some factors that explain these gaps, in particular the difference in origin and purpose of each of these instruments; 3) qualitative analysis of how the conceptual differences between the Ocem and the Enem translate in how philosophy appears in the exam throughout the years. I conclusion, In present some points of reflection about the prospect for philosophy on the exam in this new horizon after the publication of the new BNCC.
\end{abstract}

\section{Keywords}

High school philosophy - Large scale assessment - National curriculum.

\section{Introdução}

Este artigo analisa a adesão dos itens de filosofia do Exame Nacional do Ensino Médio (Enem) às Orientações Curriculares Nacionais para o Ensino Médio (Ocem) (BRASIL, 2006), como um estudo de caso da relação entre referencial curricular e avaliação em larga escala, usando como referencial teórico o ciclo de políticas de Stephen Ball e Richard Bowe (BALL; BOWE, 1992; BOWE; BALL; GOLD, 1992; MAINARDES, 2006). Este estudo tornase particularmente relevante dada, por um lado, a intermitência da filosofia nessa etapa de ensino (cf. BENJAMIN, 1990; GARRET, 1967; HEGEL, 1822; MOORE, 1967; BRASIL, 1999, 
2006; ALVES, 2002; MACED0, 2011; GALLO, 2013), e, por outro, a iminente reformulação do exame, a partir da publicação da Base Nacional Comum Curricular (BRASIL, 2018b). Por tratar de filosofia no ensino médio enquanto política educacional, este estudo inserese assim na intersecção entre filosofia, educação e política pública.

Mas por que analisar a presença da filosofia no Enem em termos dos documentos curriculares anteriores? Em particular, qual a contribuição específica que uma análise das Ocem traz para esse debate? Como o ciclo de políticas de Ball e Bowe contribui para essa reflexão?

Referenciais curriculares não surgem nem se materializam no vácuo, mas são frutos e reflexo de debates e disputas sociopolíticas, em uma dinâmica que teóricos como Ball e Bowe chamam de ciclo de políticas (BALL; BOWE, 1992; BOWE; BALL; GOLD, 1992; MAINARDES, 2006). Sob o ponto de vista deste aparato teórico, a "formação" e "implementação" de políticas não se dá de maneira linear e estanque, e sim a partir de uma variedade incontável de interações entre micro e macro esferas (políticas, educacionais e sociais, em nível local, nacional e global) de maneira contínua e nunca completa. Tendo como pano de fundo este referencial teórico, este artigo analisa a filosofia enquanto política educacional para o ensino médio nas últimas décadas, com atenção especial para a maneira como a interação entre Ocem e Enem insere-se nesse contexto.

Apesar da estipulação da Lei de Diretrizes e Bases (LDB) de que "os conteúdos, as metodologias e as formas de avaliação serão organizados de tal forma que ao final do ensino médio o educando demonstre [...] domínio dos conhecimentos de Filosofia e de Sociologia necessários ao exercício da cidadania" (BRASIL, 1996, art. 36), nos quase vinte cinco anos desde a publicação da Lei de Diretrizes e Bases em 1996, a presença da filosofia no ensino médio não tem sido nem linear, nem garantida, seja na legislação, nos referenciais curriculares (ALVES, 2002; GALLO, 2013) ou nas avaliações em larga escala, em particular no Enem (MACED0, 2015, 2021a, 2021b).

Por um lado, vemos que os referenciais curriculares publicados nos primeiros dez anos da vigência da LDB ecoam e aprofundam o estipulado no artigo 36 em relação à oferta da filosofia no ensino médio. Este é o caso, por exemplo, da Resolução CEB/CNE nº 03, de 26 de junho de 1998, que institui as Diretrizes Curriculares Nacionais para o Ensino Médio, por sua vez detalhadas no Parecer da CEB/CNE n 15 , aprovado em 01 de junho de 1998. Também é o caso de documentos posteriores, que trazem capítulos específicos para cada componente curricular, incluindo a filosofia. Nesse grupo inserem-se os Parâmetros Curriculares Nacionais (PCNs), de 1999; as Orientações Educacionais Complementares aos Parâmetros Curriculares Nacionais (PCN+), de 2002; e as Orientações Curriculares Nacionais para o Ensino Médio (Ocem), de 2006. Essa valorização da filosofia no ensino médio nesse período acompanha iniciativas internacionais, incentivadas pela UNESCO (DROIT, 1995; JOPLIN, 2000; UNESCO, 2005, 2007; MCDONOUGH; BOYD, 2009).

Foi somente após a publicação da Lei no 11.684/08, que alterava o artigo 36 da LDB de forma a tornar filosofia e sociologia obrigatórias no Ensino Médio, e das Diretrizes Curriculares Nacionais para o Ensino Médio de 2012 (Resolução CNE n 02/12), que a filosofia começou a aparecer de maneira mais constante no Enem (MACED0, 2015). Entretanto, oito anos depois de publicada, essa mesma lei foi revogada pela Medida 
Provisória $\mathrm{n}^{\circ}$ 746, de 22 de setembro de 2016, que alterava a LDB de forma a instituir o Novo Ensino Médio. Essa Medida Provisória, por sua vez, quando convertida na Lei $\mathrm{n}^{\circ}$ 13.415, de 16 de fevereiro de 2017, retomou a obrigatoriedade da filosofia (art. 35, parágrafo 2), após manifestação de vários setores da sociedade.

As Diretrizes Curriculares Nacionais para o Ensino Médio (Resolução CNE n ${ }^{\circ}$ 03/2018) e a Base Nacional Comum Curricular (BNCC), publicada em 04 de dezembro de 2018, reafirmam a obrigatoriedade da filosofia no ensino médio. A BNCC traz a filosofia como integrante da área de Ciências Humanas e Sociais Aplicadas (BRASIL, 2018b, p. 547). Já a resolução CNE n 03/2018 estabelece que "as matrizes do Exame Nacional do Ensino Médio (Enem) e dos demais processos seletivos para acesso à educação superior deverão necessariamente ser elaboradas em consonância com a Base Nacional Comum Curricular (BNCC)” (BRASIL, 2018a, artigo 32). Assim, dada a publicação da BNCC, uma questão de central importância é o debate sobre como o documento será operacionalizado, em particular no Exame Nacional do Ensino Médio (Enem), e em especial no que diz respeito à presença da filosofia no exame.

Nesse sentido, é proveitoso examinar as experiências anteriores. Entre os referenciais curriculares produzidos desde a publicação da LDB, as Ocem foram selecionadas para este estudo de caso, por alguns motivos. Este artigo insere-se em um projeto maior de estudo da presença da filosofia no Enem em termos dos referenciais curriculares publicados em sua vigência, sendo esse o módulo específico destinado às Ocem. Este documento merece um estudo específico por outros motivos ainda. Primeiro, mesmo havendo referenciais curriculares posteriores às 0cem, elas são os documentos oficiais mais recentes entre os três que dedicam um capítulo específico à filosofıa no ensino médio, permitindo assim uma análise mais aprofundada das expectativas para a área nesta etapa.

Além disso, mesmo não tendo valor normativo sobre o Enem, as Ocem propõem conteúdos para o ensino médio, sendo de se esperar certo nível de adesão entre os dois instrumentos, ainda que com lacunas decorrentes de terem sido criados independentes um do outro. Como disposto nas próprias 0cem: "para que o aluno desenvolva as competências esperadas ao final do ensino médio, não pode haver uma separação entre conteúdo, metodologia e formas de avaliação" (BRASIL, 2006, p. 36). Porém, não só levou alguns anos para as 0cem começarem a repercutir no Enem, como ainda hoje, mais de doze anos depois, há lacunas na articulação entre os dois instrumentos, as quais se manifestam nas duas direções: tanto em termos dos conteúdos das 0cem não trabalhados no exame, quanto a questões de filosofia aplicadas no Enem abrangendo tópicos não previstos nas Ocem.

As discrepâncias entre 0cem e Enem na área de filosofia não só revelam limitações de ambas em relação a esse campo de conhecimento, como também insuficiência na articulação entre referencial curricular e avaliação em larga escala. As ressalvas que o componente de filosofia das Ocem manifesta em relação a seus precedentes na linhagem de referenciais curriculares para o ensino médio por um lado, bem como sua origem na elaboração do Enade (Exame Nacional de Desempenho dos Estudantes) de 2005, por outro, configuram ótimos exemplos de como políticas educacionais estão interligadas, 
influenciando e tensionando umas às outras, conforme modelo teórico de Ball e Bowe (BALL; BOWE, 1992; BOWE; BALL; GOLD, 1992; BALL, 1998; MAINARDES, 2006).

A proposta deste artigo é apresentar uma análise dos itens de Ciências Humanas do Enem entre 1998 e 2018 em termos dos conteúdos sugeridos no componente de filosofia nas Ocem. 0 estudo divide-se em três partes. Na primeira, apresenta-se um panorama quantitativo da cobertura dos conteúdos de filosofia das Ocem ao longo dos vinte anos do Enem, identificando as lacunas que ainda persistem. Na segunda, examinam-se alguns dos motivos que explicam essas lacunas, em particular as diferenças nas origens e objetivos desses dois instrumentos, que por sua parte revelam também lacunas conceituais em relação ao que é esperado da educação básica e do papel da filosofia nela. Na terceira parte, é apresentada uma análise qualitativa de como essas divergências conceituais entre as Ocem e o Enem manifestam-se nas temáticas de filosofia abordadas na prova ao longo dos anos. Como conclusão, apresentam-se alguns pontos de reflexão a respeito das perspectivas e desafios que a BNCC oferece em relação às lacunas identificadas no corpo deste artigo no que se refere à presença da filosofia no exame nesse novo horizonte.

\section{Análise quantitativa}

Seguindo Ball e Bowe (1992), uma das teses defendidas neste artigo é a de que referenciais curriculares não se materializam de forma imediata nem garantida, seja nas escolas seja na avaliação de larga escala. Nesse sentido, é sintomático que o primeiro item de filosofia no Enem após a publicação das Ocem tenha sido aplicado três anos depois, em 2009, ano em que o exame foi reformulado. Nos cinco anos imediatamente posteriores às Ocem, as provas do Enem trouxeram somente oito itens de filosofia: em 2009, houve apenas um item de filosofia no exame; em 2010, foram seis itens; e em 2011 novamente houve apenas um item associado à área, ainda que de maneira superficial (MACEDO, 2015).

Parte do motivo pelo qual a filosofia demorou a se materializar no exame pode ser atribuída ao fato de só ter se tornado obrigatória a partir de 2008. Assim, mesmo na matriz anterior do exame, de 1998, a filosofia não era muito presente no Enem. De fato, nas sete edições entre a publicação dos PCN+ em 2002, por exemplo, e a reformulação do Enem em 2009, houve apenas um único item de filosofia no exame, em 2003 (MACED0, 2015).

Só a partir de 2012 percebe-se uma presença consolidada da filosofia na prova. A partir desse ano, o número de itens estabiliza-se em um patamar entre seis e oito, e os conteúdos se diversificam (MACED0, 2021a, 2021b). Assim, além da questão quantitativa, há melhorias qualitativas, que abarcam cobertura de uma diversidade maior de temas e abordagens característicos da filosofia, bem como uma diversidade maior de habilidades e competências da própria matriz de Ciências Humanas do Enem. Do ponto de vista das fontes utilizadas, houve um esforço perceptível de aumentar o número de textos-base de filósofos e de marcar uma abordagem filosófica, o que é significativo, não simplesmente para retornar para os clássicos pelo mero fato de serem clássicos, mas também para marcar posição nunca plenamente consolidada da disciplina no ensino médio (MACED0, 2015). 
Conforme levantamento realizado em estudo anterior (MACED0, 2021b, no prelo), no total, os setenta itens de filosofia do Enem aplicados entre 1998 e 2018 se distribuem entre 22 dos 30 conteúdos para filosofia sugeridos nas 0cem, conforme gráfico 1, a seguir:

Gráfico 1 - Quantidade de itens de Ciências Humanas do Enem por conteúdo de filosofia das Ocem (2006) - 1998-2018

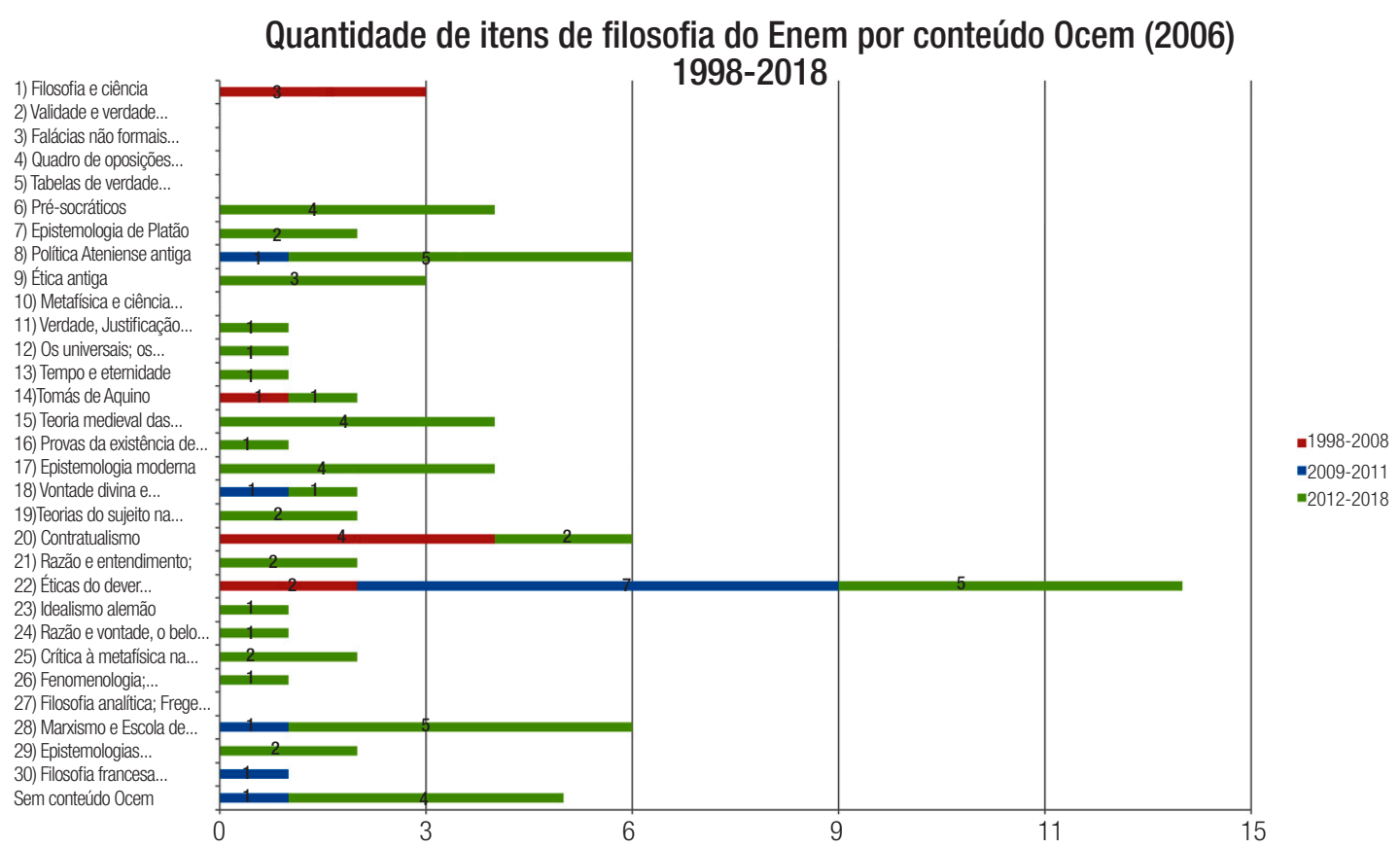

Fonte: (MACED0, 2021b, no prelo).

Conforme ilustrado nesse gráfico, ao longo de toda a história do Enem abarcada neste estudo (1998-2018), o conteúdo das Ocem mais exigido, com ampla vantagem, foi o 22, sobre ética, com doze itens a partir de 2009, mais dois itens com temáticas compatíveis no período anterior às Ocem e à nova matriz do Enem. Em segundo lugar, com seis itens cada, vieram o conteúdo 08, "política ateniense antiga", e o conteúdo 28, "marxismo e Escola de Frankfurt”, todos aplicados depois de 2009. Assim, os três conteúdos de filosofia das Ocem mais cobrados no Enem envolvem questões de cidadania, dentro do escopo da filosofia política e da ética, totalizando vinte e seis itens.

Por outro lado, seis dos trinta conteúdos propostos pelas Ocem permanecem sem cobertura no Enem nos doze anos desde sua publicação até a prova de 2018 (MACEDO, 2021b). São eles:

2) validade e verdade; proposição e argumento;

3) falácias não formais; reconhecimento de argumentos; conteúdo e forma;

4) quadro de oposições entre proposições categóricas; inferências imediatas em contexto categórico; conteúdo existencial e proposições categóricas; 
5) tabelas de verdade; cálculo proposicional;

10) conceitos centrais da metafísica aristotélica; a teoria da ciência aristotélica; e

27) filosofia analítica; Frege, Russell e Wittgenstein; o Círculo de Viena.

Essa discrepância leva a algumas perguntas: o que explica essa lacuna entre referencial curricular e sua materialização na avaliação em larga escala? Tal lacuna pode ser corrigida ou pelo menos mitigada na transição entre a BNCC e o novo Enem?

Como argumentado, parte do motivo pelo qual levou tanto tempo para a filosofia se materializar no Enem não é uma falha específica das 0cem, mas relativa a outros fatores, como o fato de sua obrigatoriedade enquanto disciplina não ter sido firmada até 2008, bem como o fato de políticas públicas terem certo tempo de maturação. Mesmo assim, após doze anos, seria de se esperar maior adesão entre esses dois instrumentos de política educacional para o ensino médio. Porém, como argumento a seguir, as lacunas entre Ocem e Enem não são apenas de ordem temporal, mas também conceitual, tendo base nas suas diferentes origens e objetivos. Nas próximas seções, analiso com maior profundidade esses aspectos.

\section{Retorno às origens}

Referenciais curriculares não surgem no vácuo, nem são implementados de maneira automática, como por fiat, mas são frutos de processos cíclicos, orgânicos e interdependentes em que a avaliação tem importância crescente nos últimos anos (BALL; BOWE, 1992; BOWE; BALL; GOLD, 1992). Para fins de análise, uma maneira comum e bastante simplificada de visualizar a interação entre referencial curricular e avaliação em larga escala é conhecido como ciclo PDCA, do inglês Plan (Planejar), Do (Fazer), Check (Verificar), Act (Agir) (DEMING, 1982). Nesse modelo, os documentos curriculares corresponderiam à primeira etapa (planejar); a implementação nas redes corresponderia à segunda etapa (fazer), a avaliação, no caso o Enem, corresponderia à terceira etapa (verificar), gerando insumos para um novo ciclo de PDCA de políticas para o ensino médio. ${ }^{2}$ A partir desse modelo, os diferentes referenciais curriculares elaborados desde a LDB poderiam ser considerados como parte de uma linhagem de documentos que, ao longo dos anos, foi sendo transformada ciclicamente, não só influenciando o exame, mas também sendo influenciada por ele (ver também MACED0, 2021a).

Pensar que referenciais curriculares não surgem no vácuo quer dizer pensar, por um lado, nas influências que eles exercem uns nos outros enquanto parte da rede de políticas educacionais para a filosofia no ensino médio, às vezes complementando-se, às vezes se contradizendo. 0 que Ball e Bowe detectam em textos de políticas educacionais em geral se aplica de forma contundente no que diz respeito às políticas educacionais para a filosofia no ensino médio, seus respectivos conceitos-chave e suas representações:

2- Sobre o uso do modelo gerencial nas políticas públicas brasileiras, ver, por exemplo, Jannuzzi, 2005. Sobre a apropriação desse tipo de modelo em políticas educacionais ver, por exemplo, Bowe; Ball; Gold (1992); Ball (1998). 
Tais textos não são, necessariamente, internamente coerentes e claros, e podem também ser contraditórios. Eles podem usar os termos-chave de modo diverso. A política não é feita e finalizada no momento legislativo e os textos precisam ser lidos com relação ao tempo e ao local específico de sua produção. Os textos políticos são o resultado de disputas e acordos, pois os grupos que atuam dentro dos diferentes lugares da produção de textos competem para controlar as representações da política. (BOWE et al., 1992 apud MAINARDES, 2006, p. 52).

Assim, embora dialoguem teoricamente com os PCNs e PCN+ (BRASIL, 2006, p. 8), as Ocem trazem em relação a esses documentos, como argumenta Silvio Gallo, "perspectivas distintas e por vezes inconciliáveis" (GALLO, 2013, p. 426). Apesar da centralidade que as Ocem atribuem à formação do licenciado em filosofia no componente dedicado à área, para o profissional de filosofia seja em sala de aula, nas universidades, nas diferentes esferas da administração pública e privada, a transição entre os documentos exigiu e exige muito esforço para ver essas concepções como minimamente complementares e para redirecionar sua prática de forma a manter coerência tanto com o documento como com sua formação profissional. Ao analisar as Ocem como parte de uma rede de políticas educacionais para o ensino médio, da qual o Enem e a nova BNCC também são parte, este artigo visa contribuir para o fortalecimento da filosofia no ensino médio, ao destacar pontos de continuidade e pontos de tensão entre nodos anteriores desta rede.

0 modelo PDCA, portanto, pode ser considerado uma simplificação por vários motivos, entre eles o fato de que nenhuma política pública se encontra isolada de outras. Além das influências que o Enem e posteriormente a BNCC recebem de sua linhagem de políticas educacionais para o ensino médio, outras influências também devem ser levadas em consideração. Isso envolve pensar também nas influências que esses instrumentos recebem de outras políticas educacionais, mesmo que não necessariamente para a filosofia ou não necessariamente para o ensino médio.

Como cada política em tese teria seu próprio ciclo PDCA, com seus diferentes atores, tempos políticos e esferas de atuação, os polos de influência que umas exercem nas outras sofrem variações e interferências ao longo do tempo. 0 ciclo de políticas de Ball e Bowe é, portanto, mais adequado enquanto modelo teórico, entre outros motivos, pela ênfase dada a essas interações, tensões e influências das diferentes políticas umas nas outras. São como as influências gravitacionais que os diferentes corpos celestes de diferentes magnitudes e órbitas exercem uns nos outros. Como sintetiza Mainardes:

Esses contextos estão interrelacionados, não têm uma dimensão temporal ou sequencial e não são etapas lineares. Cada um desses contextos apresenta arenas, lugares e grupos de interesse e cada um deles envolve disputas e embates. (BOWE et al., 1992 apud MAINARDES, 2006, p. 50).

Contrastar o componente de filosofia das Ocem com a abordagem de temas filosóficos nas provas de Ciências Humanas do Enem apresenta-se como um bom estudo de caso para pensar a filosofia no ensino médio, porque fornece um forte exemplo de como políticas curriculares são frutos de processos cíclicos, orgânicos e interdependentes em que a avaliação cumpre papel importante. Por exemplo, o próprio corpo do capítulo 
de filosofia das Ocem descreve forma explícita como sua origem e processo de produção derivam de um outro processo, no caso o Enade:

0 processo de redação deste documento coincidiu com um novo quadro institucional para a disciplina Filosofia. Em primeiro lugar, os cursos de graduação em Filosofia passaram a ser submetidos à avaliação institucional, tendo sido nomeada uma comissão para elaborar os critérios para a futura elaboração de provas para o Enade 2005 da área de Filosofia. Os trabalhos dessa comissão certamente contribuíram para o amadurecimento das discussões sobre a composição da disciplina para o ensino médio, na medida em que se afırmaram algumas posições acerca da graduação e das competências esperadas do profissional formado nos cursos de licenciatura em Filosofia. (BRASIL, 2006, p. 19)3.

A relação entre as Ocem e o Enade de 2005 ilustram como diferentes ciclos de políticas, em suas diferentes etapas, intersectam e influenciam um ao outro. Nesse caso, o Enade, para além de exercer sua função primária de monitoramento dentro do ciclo de políticas públicas voltadas para a qualidade do ensino superior, atua também enquanto subsídio na elaboração de referenciais curriculares orientadores de um ciclo em outro âmbito, no caso o ensino médio. 0 ciclo PDCA que iniciaria com 1) normativa legal (Ocem); 2) implementação (filosofia no ensino médio); 3) monitoramento (Enem) não só é precedido temporalmente, mas é também substancialmente influenciado por um instrumento de monitoramento de outro ciclo de políticas públicas.

Por sua vez, a matriz de 2009 do Enem tem sua origem no Exame Nacional para Certificação de Competência de Jovens e Adultos (Encceja) (BRASIL, 2014, p. 7). Assim, enquanto o componente de filosofia das Ocem, com sua origem no Enade, tem uma proposta mais acadêmica, a matriz do Enem, com sua origem no Encceja, vai na direção oposta. Pela característica herdada do Encceja de medir competências a partir de experiências de vida fora do universo escolar e acadêmico, a matriz de Ciências Humanas do Enem de $2009^{4}$ não oferece muito espaço para itens de filosofia (GALLO, 2013; MACEDO, 2021a).

Por outro lado, repetidas vezes os autores do componente de filosofia das Ocem enfatizam noções como a centralidade da História da Filosofia como "pedra de toque" (p. 31, p. 32); o "primado do texto filosófico" (p. 17, p. 37), que é "matéria precípua" da filosofia, "em conteúdo e forma" (p. 32); a imprescindibilidade do recurso à "tradição filosófica" (p. 32); a "importância de uma técnica exegética" (p. 32); a especificidade da contribuição da filosofia para a argumentação e leitura (p. 30); tendo muitas reservas quanto a quaisquer menção na legislação ou em outros documentos em relação à educação básica enquanto formação para o mundo do trabalho (BRASIL, 2006, p. 19, p. 26, p. 29).

Essa relação entre Enem e Encceja por um lado, e Ocem e Enade por outro, ilustra como diferentes ciclos de políticas, em suas diferentes etapas, longe de serem lineares, intersectam, influenciam e tencionam uns aos outros. Para além de origens e objetivos

3- "Uma indicação clara do que se espera do professor de Filosofia no ensino médio pode ser encontrada nas Diretrizes Curriculares aos Cursos de Graduação em Filosofia e pela Portaria INEP no 171, de 24 de agosto de 2005, que instituiu o Exame Nacional de Desempenho dos Estudantes (Enade) de Filosofia, que também apresenta as habilidades e as competências esperadas do profissional responsável pela implementação das diretrizes para o ensino médio." (BRASIL, 2006, p. 31).

4- A matriz de Ciências Humanas do Enem de 2009 está disponível em: http://download.inep.gov.br/download/enem/matriz_referencia.pdf 
distintos e falta de uma proposição articulada entre Ocem e Enem, há também uma lacuna conceitual entre esses dois instrumentos. Essa lacuna envolve conceitos-chave, como ética e cidadania, e competências e habilidades para o mundo do trabalho, e as expectativas em relação à educação básica em geral e à filosofia em particular em relação ao desenvolvimento dessas características nos egressos do ensino médio ou no que se é esperado de adultos mesmo que não tenham completado essa etapa escolar.

Na próxima seção, exploro a relação tensa que o componente de filosofia das Ocem tem tanto com a linhagem de referenciais curriculares que as precedem, a contar da LDB, quanto com a forma que essas tensões contrastam com a maneira em que a filosofia tem sido abordada no Enem ao longo dos anos.

\section{Análise qualitativa}

Entre as críticas que os autores do componente de filosofia das Ocem apresentam em relação aos referenciais curriculares anteriores, em particular aos PCNs, estão sua suposta ambiguidade, por um lado, e unilateralidade, por outro:

Os PCN vigentes para a disciplina, assim como os anteriores, sofrem da ambiguidade que pretenderam curar e muitas vezes oscilam entre enunciar pouco e enunciar excessivamente. Assim, ao lado de uma cautela excessiva, podemos encontrar passos por demais doutrinários que terminam por roubar à Filosofia um de seus aspectos mais ricos, a saber, a multiplicidade de perspectivas, que não deve ser reduzida a uma voz unilateral. Mostrou-se, pois, necessária uma reformulação que evite imposições doutrinárias, mesmo quando resultantes das melhores intenções. (BRASIL, 2006, p. 18).

Contudo, as próprias Ocem não são imunes a esses mesmos problemas. No que diz respeito à seção dedicada à filosofia, as Ocem (BRASIL, 2006) são um documento ambíguo, não só em relação aos referenciais curriculares anteriores, como os PCNs e a própria LDB (p. 26, p. 28), mas também por serem internamente contraditórias: no que diz respeito ao conceito de cidadania (p. 15, p. 18, p. 19), de competência (p. 19, p. 29, p. 30), até mesmo em relação à ambiguidade (p. 16, p. 21). Em relação à noção de competência, por exemplo, as Ocem, por um lado, veem a importância de competências ao invés de conteúdos (p. 29). Ao mesmo tempo, elas veem com preocupação o conceito de competência (p. 19, p. 29, p. 30) e acabam por propor conteúdos (p. 34), conforme ilustrado na primeira parte deste artigo.

Em termos da noção de cidadania, embora o componente de Ciências Humanas mencione política, inclusão, diálogo, gestão participativa, esses elementos estão ausentes dos conteúdos para a filosofia propostos no documento. Para os autores do componente de filosofia das Ocem, educar para a cidadania é "um desafio" (BRASIL, 2006, p. 15, p. 24). Por meio de uma varredura rápida sobre o conceito nos referenciais anteriores, os autores deixam transparecer certa relutância em admitir ética e cidadania como parte do escopo da formação filosófica, considerando-as na verdade como parte da educação geral, não especificamente da filosofia (p. 25): "Uma vez que é possivel formar cidadãos sem a contribuição formal da Filosofia, seria certamente um erro pensar que a ela, 
exclusivamente, caberia tal papel” (BRASIL, 2006, p. 26). Essa função específica, na visão de filosofia das Ocem, é a competência argumentativa - leitura, linguagem, lógica:

\begin{abstract}
A pergunta que se coloca é: qual a contribuição específica da Filosofia em relação ao exercício da cidadania para essa etapa da formação? A resposta a essa questão destaca o papel peculiar da filosofia no desenvolvimento da competência geral de fala, leitura e escrita - competência aqui compreendida de um modo bastante especial e ligada à natureza argumentativa da Filosofia e à sua tradição histórica. Cabe, então, especificamente à Filosofıa a capacidade de análise, de reconstrução racional e de crítica, a partir da compreensão de que tomar posições diante de textos propostos de qualquer tipo (tanto textos filosóficos quanto textos não filosóficos e formações discursivas não explicitadas em textos) e emitir opiniões acerca deles é um pressuposto indispensável para o exercício da cidadania. (BRASIL, 2006, p. 26).
\end{abstract}

Dessa forma, apesar de reconhecer a centralidade de questões éticas e políticas no cotidiano ${ }^{5}$, quanto à formação em filosofia política e ética, as 0cem trazem uma rejeição explícita:

[A] simples alusão a questões éticas não é ética, nem filosofia política a mera menção a questões políticas, não sendo o desejo de formar cidadãos o suficiente para uma leitura filosófica, uma vez que tampouco é prerrogativa exclusiva da Filosofia um pensamento crítico ou a preocupação com os destinos da humanidade. (BRASIL, 2006, p. 18).

Essa rejeição reflete-se depois nos conteúdos sugeridos e mostram lacunas importantes nas Ocem, principalmente no campo de filosofia política e ética. ${ }^{6}$ À ética são reservados apenas dois conteúdos: o conteúdo 9) "a ética antiga; Platão, Aristóteles e filósofos helenistas"; e o conteúdo 22) "éticas do dever; fundamentações da moral; autonomia do sujeito". Já a filosofia política encontra espaço em quatro conteúdos: 8) "a política antiga; a República de Platão; a Política de Aristóteles"; 20) "o contratualismo"; 28) "marxismo e Escola de Frankfurt”; e 30) "Filosofia francesa contemporânea; Foucault; Deleuze”.

No que diz respeito à cobertura dos conteúdos de filosofia das Ocem nas provas de Ciências Humanas do Enem, a carência de sugestões por parte daquele documento no campo da ética explica, por um lado, a abundância de itens do exame mais próximos ao conteúdo 22, que se torna um guarda-chuva genérico para todos os itens de ética que

\footnotetext{
5- "Também são prementes as inquietações de cunho ético, que são suscitadas por episódios políticos nos cenários nacional e internacional, além dos debates travados em torno dos critérios de utilização das descobertas científicas. Situação análoga foi detectada em outras instâncias de discussão pública e mobilização social, como o evidenciam, por exemplo, os debates relativos à conduta de veículos de comunicação, tais como televisão e rádio. Ainda que, na grande maioria dos casos, não se possa falar de uma conceituação rigorosa, não se pode ignorar que nessas discussões estão envolvidos temas, noções e critérios de ordem filosófica". (BRASIL, 2006, p. 15).

6- "Podemos constatar, novamente, uma convergência entre o papel educador da Filosofia e a educação para a cidadania que se postulou anteriormente. Os conhecimentos necessários à cidadania, à medida que se traduzem em competências, não coincidem, necessariamente, com conteúdos, digamos, de ética e de filosofia política. Ao contrário, destacam o que, sem dúvida, é a contribuição mais importante da Filosofia: fazer o estudante aceder a uma competência discursivo-filosófica. Espera-se da Filosofia, como foi apontado anteriormente, o desenvolvimento geral de competências comunicativas, o que implica um tipo de leitura, envolvendo capacidade de análise, de interpretação, de reconstrução racional e de crítica. Com isso, a possibilidade de tomar posição por sim ou por não, de concordar ou não com os propósitos do texto é um pressuposto necessário e decisivo para o exercício da autonomia e, por conseguinte, da cidadania”. (BRASIL, 2006, p. 30-31).
} 
saem do escopo da filosofia antiga. No quesito filosofia política, essa lacuna envolve não só toda discussão acerca da democracia do período moderno e contemporâneo, mas mesmo questões de filosofia política fora da antiguidade.

Assim, um item como o 45 da prova de $2010^{7}$, que utilizava um quadrinho da Mafalda para trabalhar a questão de democracia e despotismo, não encontra espaço nas Ocem (MACED0, 2015). Também não há espaço nas Ocem para itens como o 17 da prova de 2015, que trazia texto de Tomás de Aquino sobre a monarquia. Pela ausência de sugestões na área de filosofia política, é difícil pensar qual conteúdo das Ocem abririam espaço para esse tipo de questão. Silvio Ricardo Gomes Carneiro, em seu texto "0 Enem e a leitura de textos filosóficos: análise de alguns parâmetros para a sala de aula" (2015), por exemplo, considera que esse item atende o conteúdo 18, "vontade divina e liberdade humana”, embora não haja qualquer menção à questão divina no trecho apresentado. Por tratar da questão da ação humana e o bem comum, central na ética, neste estudo o conteúdo considerado mais próximo foi o recorrente conteúdo 22.

Mais recentemente, na prova de 2018, outra questão que não dialoga com a concepção das Ocem foi o item 90, que traz um texto de Bobbio sobre o teórico Hans Kelsen acerca do caráter individualista das democracias contemporâneas. Um exemplo de item de filosofia política mais adequado à proposta das 0cem é o item 52 da mesma prova, que pede para o respondente comparar os pensamentos de Hobbes e Rousseau. Este item trabalha o conteúdo 20 das 0cem, "o contratualismo". Na prova de 2017, o item 84, sobre Habermas, como em 2012, entraria no conteúdo 28) "marxismo e Escola de Frankfurt", por falta de um espaço mais adequado. Já o item 64, que pede para o respondente associar o pensamento de John Rawls ao liberalismo do período moderno, é mais difícil de pensar em termos das 0cem. 0 conteúdo que talvez permitisse esse tipo de exercício seria o 20, "o contratualismo", pela relação que ele tem com o liberalismo.

Além desses, há muitos outros itens de filosofia política no Enem que dialogam com as Ocem apenas tangencialmente. Por exemplo, o item 7 de 2012, por exemplo, que aborda a visão de Montesquieu sobre a liberdade política. Montesquieu é um clássico da filosofia política, a ponto de ter subtema só para ele nos PCN+, dentro do tema I.2, "A democracia contemporânea”. Por outro lado, em termos das 0cem, não é óbvio qual conteúdo abarcaria o trabalho desse autor. Carneiro (2015), por exemplo, considera que nenhum conteúdo das Ocem se aplica a este item. Para os fins deste estudo, pela vinculação teórica do autor e temática trabalhada no item, ele atende o conteúdo 20, “o contratualismo”. Já o item 09 da mesma prova, sobre Habermas, também seria um conteúdo de democracia se houvesse um, mas na falta dele, ele pode ser classificado como parte do conteúdo 28, "marxismo e Escola de Frankfurt", pela vinculação do autor.

Em relação ao conteúdo 22, "éticas do dever; fundamentações da moral; autonomia do sujeito", de todos os doze itens do Enem entre 2006 e 2018 que trabalham de alguma forma esse conteúdo, os que o fazem com maior propriedade são o item 02 da prova de 2012, sobre a concepção de maioridade em Kant, e o item 85 de 2017, sobre o imperativo categórico. Outros itens do período moderno e contemporâneo que lidam com algum

7- Nos exemplos utilizados, o posicionamento de cada questão na prova toma como referência o caderno azul. 
aspecto de ética ou autonomia tem nesse conteúdo o ponto de contato mais próximo com as 0cem, mesmo não se adequando integralmente. Ele acaba por abarcar assim questões como o item 10 de 2013 acerca de motivações humanas em Maquiavel; o item 3 de 2017 sobre o pensamento autônomo na filosofia de Paulo Freire e o item 48 da mesma prova sobre o utilitarismo de Bentham.

Assim, apesar de todo esforço dos autores do componente de filosofia das Ocem de se distanciarem de questões sobre ética, política, cidadania (BRASIL, 2006, p. 18, p. 19, p. 24, p. 32), essas questões abordam temas que são caros à filosofia, e de maneira relevante para o estudante de ensino médio. Além disso, longe de materializarem a preocupação do documento em termos de doutrinação ou "ingênua cobrança de univocidade" (p. 21), elas mostram-se variadas o suficiente para satisfazer os requisitos enunciados nas próprias Ocem em relação à multiplicidade de perspectivas.

Para concluir este artigo, na próxima seção apresento algumas perspectivas e desafios que a BNCC apresenta em relação à filosofia no Enem, a partir dos pontos levantados ao longo deste estudo.

\section{Conclusão}

Neste artigo, foram abordadas algumas limitações e lacunas na área de filosofia entre as Ocem e o Enem. Argumentei que, embora muitas dessas lacunas e limitações sejam internas a cada um desses instrumentos, muito da discrepância entre os dois se deve a uma falta de articulação entre eles. Essa falta de articulação deve-se, em parte, às diferentes origens e objetivos de cada um desses documentos, e em parte, às dinâmicas próprias do que Stephen Ball e Richard Bowe chamam de ciclo de políticas.

Mas qual contribuição que uma análise como esta, sobre a adesão dos itens de filosofia às Ocem, traz para a reflexão com relação aos espaços dedicados à filosofia na BNCC e perspectivas para a área a partir desse novo cenário?

Como parte da linhagem de referenciais das quais a BNCC faz parte, olhar para as Ocem contribui como um benchmark para avaliar avanços e pontos de atenção, tanto internos à filosofia em cada um desses instrumentos, quanto em relação à articulação entre eles enquanto políticas educacionais para o ensino médio.

Excluir do currículo do ensino médio questões sobre ética e cidadania, como fazem as 0cem, é reservar essa discussão a um grupo extremamente restrito, que consiste em pessoas que: 1) já concluíram o ensino médio, 2) conseguiram alcançar uma vaga na universidade e 3) optaram por estudar filosofia. Mas a partir do momento que a filosofia no ensino médio é obrigatória, como é no cenário pós-BNCC e reforma do ensino médio, com ênfase no protagonismo juvenil (cf. BRASIL, 2018b, p. 465, p. 468, p. 471-472, p. 478-479, p. 562), nada mais coerente que questões sobre escolha, autonomia e forma de organização do Estado sejam também debatidas por aqueles a quem julgamos este estudo ser benéfico. Ao minimizar a importância de questões de ética e cidadania no ensino de filosofia no ensino médio, perde-se uma oportunidade de expandir esse debate justamente com as pessoas mais diretamente envolvidas na educação básica, que são os estudantes e professores de filosofia do ensino médio. (BANDMAN, 1982; GEHRETT, 2000; PINTO; 
McDONOUGH; BOYD, 2009; BALL, BOWE \& GOULD, 1992; SILVA, 2020; SÜSSEKIND; MASKE, 2020).

Felizmente, a BNCC oferece mais abertura para temas de filosofia em comparação com as Ocem, em particular nas áreas de ética e de filosofia política. Temas de ética encontram espaço especial na competência 5: "Identificar e combater as diversas formas de injustiça, preconceito e violência, adotando princípios éticos, democráticos, inclusivos e solidários, e respeitando os Direitos Humanos". Já os temas de filosofia política podem ser trabalhados na competência 6, "Participar do debate público de forma crítica, respeitando diferentes posições e fazendo escolhas alinhadas ao exercício da cidadania e ao seu projeto de vida, com liberdade, autonomia, consciência crítica e responsabilidade”. (BRASIL, 2018b, p. 577-578).

As habilidades propostas em cada uma dessas competências dão margem para ampliar ainda mais o espaço para ética e filosofia política que na matriz de referência do Enem vêm sido exercidas por habilidades como a H12, "Analisar o papel da justiça como instituição na organização das sociedades", a habilidade H23, "Analisar a importância dos valores éticos na estruturação política das sociedades", a H24, "Relacionar cidadania e democracia na organização das sociedades", a H25, "Identificar estratégias que promovam formas de inclusão social.” Já aqui é possível observar uma adesão conceitual entre BNCC e Enem mais próxima do que houve entre o exame e as Ocem. Essa adesão reflete outro ponto levantado neste estudo, que é a questão da origem e dos objetivos de cada um desses instrumentos de políticas educacionais.

A proximidade entre BNCC e Enem remete às suas respectivas origens, de duas maneiras. Por um lado, enquanto as Ocem não mencionam o Enem, e tampouco têm caráter normativo sobre o programa de ensino das redes, a BNCC já surge concomitante com a resolução do CNE de que "as matrizes do Exame Nacional do Ensino Médio [...] deverão necessariamente ser elaboradas em consonância com a Base Nacional Comum Curricular (BNCC)" (Resolução CNE n 03/2018). Além disso, como argumento em outro artigo (MACEDO, 2021a, no prelo), muitas das habilidades de Ciências Humanas da BNCC têm teor e redação próximas a habilidades da matriz de referência do Enem, o que reforça a tese de que não é são só referenciais que exercem influência sobre o exame, mas que esse retroalimenta também, influenciando a próxima geração de referenciais curriculares.

Por um lado, essas proximidades entre Enem e BNCC já a partir de suas origens podem contribuir para minimizar algumas lacunas entre esses dois instrumentos, sejam elas temporais ou conceituais. Por outro lado, a análise aqui apresentada permite elencar alguns pontos de atenção, tanto internamente à área de filosofia nesse novo contexto, quanto em relação à articulação entre referencial curricular e avaliação em larga escala de modo mais amplo.

Mapear os pontos de adesão entre Ocem e Enem ajudam encontrar lacunas não só nas Ocem, mas também no Enem e na própria BNCC. Conforme apontado anteriormente, seis dos conteúdos propostos pelas Ocem para a filosofia permanecem sem cobertura no Enem até a prova de 2018 (conteúdos 2, 3, 5, 6, 10, 27). De certa maneira, esses conteúdos dialogam com a lógica aristotélica e têm certa aproximação com a matemática. As Ocem 
seguem nesse ponto as Diretrizes Curriculares aos Cursos de Graduação de Filosofia de 2005, ao estipular lógica entre uma das cinco grandes áreas da filosofia. ${ }^{8}$ Esse é um importante acréscimo das 0cem em relação aos PCN e PCN+, ainda não completamente incorporadas ao Enem. A situação em relação à BNCC não é muito mais propícia a esses conteúdos, tendo como pontos de contato mais próximos as habilidades EM13CHS101 e EM13CHS103 (cf. MACED0, 2021b).

Claro que a questão sobre se lógica, filosofia analítica ou teoria da ciência aristotélica devem ou não fazer parte do currículo do ensino médio não é consenso. Por isso o debate com vários setores da sociedade é tão necessário. A partir do momento em que se pensa e prescreve um desenvolvimento filosófico para jovens do ensino médio, é necessário pensar como expandir e aprofundar a intersecção entre as áreas da filosofia, da educação e da política pública. Isso envolve discussões de natureza filosófica, epistemológica, ética, política com pessoas em diferentes esferas e diferentes níveis de formação em cada uma dessas áreas. Abre-se aqui todo um leque de questões, bastante caras à filosofia, a respeito de que tipo de educação, conhecimento e sociedade esperamos não só dos nossos jovens, mas de nós também, cidadãos e participantes das diferentes esferas do convívio público (MARTIN, 1981a, 1981b, 1985a, 1985/2001; McCOLL, 1994; MILLS, 1998; SIEGEL, 2008; YOUNG, 1990, 2002; POPKEWITZ, 2020).

Retomando o ciclo de políticas de Ball e Bowe, essas interações são cruciais e estão sempre ativas, em maior ou menor grau de coesão, em algum ponto ou outro do emaranhado de micro e macro esferas que compõem a sociedade. Entretanto, como as políticas educacionais têm ciclos de diferentes durações, há alguns pontos de inflexão em que esse tipo de interação entre diferentes esferas da sociedade é particularmente crucial. 0 momento atual é um deles.

Embora seja um truísmo dizer que nenhum tempo tem volta, é importante frisar que o tempo escolar é particularmente irrecuperável. 0 tempo letivo, e o tempo escolar como um todo, é muito sensível em termos de oportunidades, expectativas e escolhas. Uma pessoa que começasse o ensino fundamental no ano de publicação das Ocem em 2006 e tivesse uma trajetória de completo êxito terminaria o ensino médio em 2018, ano em que foi publicada a Base Nacional Comum Curricular. Essa, por sua vez, havia sido preconizada na Constituição Federal de 1988 e levou trinta anos para se materializar.

Conforme exemplificado, apesar de estar longe de ser isenta das próprias lacunas e limitações, a BNCC oferece algumas possibilidades para a filosofia, especialmente se comparada com os referenciais anteriores, como as 0cem. Mesmo em relação à matriz de referência do Enem, com a qual ela tem muitos pontos em comum, a BNCC traz alguns avanços interessantes. Se não houver, contudo, um maior espaço para reflexão e debates sobre como a BNCC será operacionalizada nas avaliações de larga escala, em especial no Enem, não está garantido nem certo que esse potencial filosófico será aproveitado nesse contexto do novo ensino médio, mesmo com a reafirmação do caráter obrigatório da disciplina. Essa situação é ainda mais grave no que diz respeito às lacunas, tanto as

8- "[D]ecidiu-se que a avaliação de cursos de graduação em Filosofia deve tomar como eixo central o currículo mínimo composto pelas cinco matérias básicas: História da Filosofia, Teoria do Conhecimento, Ética, Lógica e Filosofia Geral: Problemas Metafísicos” (BRASIL, 2006, p. 20). 
apresentadas aqui quanto as tantas outras que existem. Se não houver um real esforço de interação e debate entre diferentes esferas (acadêmicas, educacionais, filosóficas, escolares, políticas e administrativas) para pensar essas questões, tais lacunas permanecerão descobertas até o surgimento do próximo documento curricular. A tomar como parâmetro os referenciais anteriores, isso pode facilmente levar mais de uma década, o que em termos educacionais equivale à formação de toda uma geração de cidadãos.

\section{Referências}

ALVES, Dalton José. A Filosofia no ensino médio: ambiguidade e contradições na LDB. Campinas: Autores Associados, 2002.

BALL, Stephen J. Big policies/small world: an introduction to international perspectives in education policy. Comparative Education, Abingdon, v. 34, n. 2, p. 119-130, 1998.

BALL, Stephen J.; BOWE, Richard. Subject departments and the 'implementation' of national curriculum policy: an overview of the issues. Journal of Curriculum Studies, London, v. 24, n. 2, p. 97-115, 1992.

BANDMAN, Bertram. The adolescent's rights to freedom, care and enlightenment. Thinking: The Journal of Philosophy for Children, Montclair, v. 4, n. 1, p. 22-27, 1982.

BENJAMIN, David. Philosophy in high school: what does it all mean? Thinking: The Journal of Philosophy for Children, Montclair, v. 8, n.4, p. 43-44, 1990.

BOWE, Richard; BALL, Stephen J.; GOLD, Anne. Reforming education \& changing schools: case studies in policy sociology. London: Routledge, 1992.

BRASIL. Lei n 9.394, de 20 de dezembro de 1996. Lei de diretrizes e bases da educação nacional. Diário Oficial da União, Brasília, DF, 23 dez. 1996.

BRASIL. Lei n 13.415, de 16 de fevereiro de 2017. Diário Oficial da União, Brasília, DF, 16 fev. 2017.

BRASIL. Conselho Nacional de Educação. Diretrizes Curriculares Nacionais para o Ensino Médio. Parecer CNE/CEB 15/1998. Brasília, DF: CNE, 1998. Disponível em: http://portal.mec.gov.br/seb/arquivos/ pdf/Par1598.pdf. Acesso em: 30 mar. 2021.

BRASIL. Conselho Nacional de Educação. Diretrizes Curriculares Nacionais para o Ensino Médio. Resolução CNE/CEB 3/2018. Diário Oficial da União, Brasília, DF, Seção 1, p. 21-24, 22 nov. 2018.

BRASIL. Instituto Nacional de Estudos e Pesquisas Educacionais (INEP). Exame Nacional do Ensino Médio (Enem): relatório pedagógico 2009-2010. Brasília, DF: INEP, 2014.

BRASIL. Instituto Nacional de Estudos e Pesquisas Educacionais (INEP). Matrizes de referências do

Enem. v. 4. Brasília, DF: INEP, 2009. 
BRASIL. Ministério da Educação (MEC). Base Nacional Comum Curricular para o Ensino Médio. Brasília, DF: MEC, 2018b.

BRASIL. Ministério da Educação (MEC). Orientações curriculares nacionais para o ensino médio: ciências humanas e suas tecnologias. v. 3. Brasília, DF: MEC, 2006.

BRASIL. Ministério da Educação (MEC). Conselho Nacional de Educação. Resolução CNE nº 03, de 04 de dezembro de 2018. Brasília, DF: MEC, 2018a.

BRASIL. Ministério da Educação (MEC). Secretaria de Educação Média e Tecnológica (SEMTEC). Orientações educacionais complementares aos Parâmetros Curriculares Nacionais. Brasília, DF: SEMTEC/MEC, 2002.

BRASIL. Ministério da Educação (MEC). Secretaria de Educação Média e Tecnológica (SEMTEC). Parâmetros Curriculares Nacionais para o Ensino Médio. Brasília, DF: SEMTEC/MEC, 1999.

CARNEIRO, Silvio Ricardo Gomes. 0 Enem e a leitura de textos filosóficos: análise de alguns parâmetros para a sala de aula. Revista do NESEF Filosofia e Ensino, Curitiba, v 6, n. 6, p. 26-42, jun./dez. 2015.

DEMING, William Edwards. Out of the crisis. Cambridge: MIT Press, 1982.

DROIT, Roger-Pol. Philosophy and democracy in the world. Paris: Unesco, 1995.

GALLO, Sílvio. Filosofia e Exame Nacional do Ensino Médio: desafios e perspectivas da avaliação. In: AVALIAÇÕES da educação básica em debate: ensino e matrizes de referências das avaliações em larga escala. Brasília, DF: INEP, 2013. p. 413-429.

GARRET, Leroy. 10 years in high school philosophy. Educational Theory, Champaign, v. 17, n. 3, p. 241 247, 1967.

GEHRETT, Christine. Doing philosophy in high school: one teacher's account. Inquiry, Huntsville, v. 19, n. 2, p. 27-35, 2000.

HEGEL, Georg. On teaching philosophy in the gymnasium. Thinking: The Journal of Philosophy for Children, Montclair, v. 2, n. 2, p. 30-33, 1822/1980.

JANNUZZI, Paulo de Martino. Indicadores para diagnóstico, monitoramento e avaliação de programas sociais no Brasil. Revista do Serviço Público, Brasília, DF, v. 56, n. 2, p. 137-160, 2005.

JOPLIN, David. "The coolest subject on the planet": how philosophy made its way in Ontario's high school". Analytic Teaching, La Crosse, v. 21, n. 2, p. 131-139, 2000.

MACED0, Ester Pereira Neves. Debater para encontrar caminhos: a evolução da presença da filosofia ao longo dos vinte anos do Enem (1998-2018). Pro-Posições, Campinas, 2021a (no prelo). 
MACEDO, Ester Pereira Neves. Filosofia no Enem: um estudo analítico dos conteúdos relativos à filosofia ao longo das edições do Enem entre 1998 e 2011. Brasília, DF: INEP, 2015.

MACED0, Ester Pereira Neves. Filosofia no Enem: 2012-2018. Brasília, DF: INEP, 2021b (no prelo).

MACEDO, Ester Pereira Neves. Philosophy of the many: high school philosophy and a politics of difference. 2011. 154 f. PhD Thesis (Doctor of Philosophy) - Graduate Department of Theory and Policy Studies, Ontario Institute for Studies in Education. University of Toronto, Toronto, 2011.

MAINARDES, Jefferson. Abordagem do ciclo de políticas: uma contribuição para a análise de políticas educacionais. Educação \& Sociedade, Campinas, v. 27, n. 94, p. 47-69, jan./abr. 2006.

MARTIN, Jane Roland. Becoming educated: a journey of alienation or integration? In: HARE, William; PORTELLI, John Peter (ed.). Philosophy of education: introductory readings. 3. ed. Calgary; Alberta: Detselig Enterprises, 1985/2001. p. 69-82.

MARTIN, Jane Roland. Needed: a new paradigm for liberal education. In: SOLTIS, Jonas (ed.). Philosophy and education. Chicago: University of Chicago Press, 1981b. p. 37-59.

MARTIN, Jane Roland. Reclaiming a conversation: the ideal of the educated woman. New Haven: Yale University Press, 1985.

MARTIN, Jane Roland. The ideal of the educated person. Educational Theory, Champaing, v. 31, n. 2, 97-110, 1981a.

McCOLL, San. Opening philosophy. Thinking: The Journal of Philosophy for Children, Montclair, v. 11, n. 3-4, p. 5-9, 1994.

McDONOUGH, Graham; BOYD, Dwight. Socrates seen in Ontario high schools (and he has not left the building!). Journal of Teaching and Learning, Richmond Hill, v. 6, n. 1, p. 55-67, 2009.

MLLLS, Charles W. Alternative epistemologies. In: ALCOFF, Linda Martin (ed.). Epistemology: the big questions. Malden: Blackwell, 1998. p. 392-410.

MOORE, Willis. Philosophy in curriculum of high school: purpose and plan of this issue. Educational Theory, Champaign, v. 17, n. 3, p. 203-204, 1967.

PINTO, Laura Elizabeth; McDONOUGH, Graham; BOYD, Dwight. What would Socrates do? An exploratory study of methods, materials and pedagogies in high school philosophy. Journal of Teaching and Learning, Richmond Hill, v. 6, n. 1, p. 69-82, 2009.

POPKEWITZ, Thomas. Estudos curriculares, história do currículo e teoria curricular: a razão da razão. Em Aberto, Brasília, DF. v. 33, n. 107, p. 47-66. jan./abr. 2020.

SIEGEL, Harvey. Why teach epistemology in schools. In: HAND, Michel; WINSTANLEY, Carrie (ed.). Philosophy in schools. New York: Continuum International, 2008. p. 78-84. 
SILVA, Francisco Thiago. 0 nacional e o comum no ensino médio: autonomia docente na organização do trabalho pedagógico. Em Aberto, Brasília, DF. v. 33, n. 107, p. 155-172. jan./abr. 2020.

SÜSSEKIND, Maria Luiza; MASKE, Jeferson. "Pendurando roupas nos varais": Base Nacional Comum Curricular, trabalho docente e qualidade. Em Aberto, Brasília, DF. v. 33, n. 107, p. 155-172. jan./abr. 2020.

UNESCO. Intersectorial strategy for philosophy. Paris: Unesco, 2005.

UNESCO. Philosophy: a school of freedom. Paris: Unesco, 2007.

YOUNG, Iris Marion. Justice and the politics of difference. Princeton: Princeton University Press, 1990.

YOUNG, Iris Marion. Inclusion and democracy. Oxford: Oxford University Press, 2002.

Recebido em: 29.08.2019

Revisado em: 03.03.2020

Aprovado em: 02.06.2020

Ester Pereira Neves de Macedo é doutora em teorias e políticas educacionais/filosofia da educação pela Universidade de Toronto / Ontario Institute for Studies in Education (2011) e pesquisadora-tecnologista no Instituto Nacional de Estudos e Pesquisas Educacionais Anísio Teixeira (INEP) desde 2013. Pesquisa desenvolvida durante estágio de pós-doutorado em Estudos comparados sobre Educação, sob a supervisão da Prof. Dra. Wivian Weller, no âmbito do grupo de pesquisa Gerações e Juventude (GERAJU), na Faculdade de Educação da Universidade de Brasília (UnB) e integrante do projeto de pesquisa: "Estudo comparado dos exames Enem (Brasil) e Gaokao (China): repercussões nos currículos do ensino médio e no acesso à educação superior de jovens brasileiros e chineses." Financiamento: FAP/DF, Edital 03/2016 Demanda Espontânea e CNPq Chamada Universal 01/2016. 